\title{
Isotopic Oxygen Exchange on Supported Ru and Au Catalysts
}

\author{
J. Schwank, 'S. Galvagno, ${ }^{2}$ and G. Parravano ${ }^{3}$ \\ Department of Chemical Engineering, University of Michigan, Ann Arbor, Michigan 48109
}

Received September 4, 1979; revised January 9, 1980

\begin{abstract}
The isotopic exchange reaction of molecular oxygen is applied to supported ruthenium and gold catalysts. The results on supported ruthenium are similar to those on $\mathrm{RuO}_{2}$. The exchange reaction seems to be unaffected by differences in particle size or nature of the support $\left(\mathrm{MgO}\right.$ or $\mathrm{SiO}_{2}$, respectively). The heterogeneous exchange kinetics deviate from an exponential law. This indicates the presence of nonuniformities on the catalyst surface and/or a contribution of oxygen diffusion. On supported gold, high exchange activity and massive uptake of labeled oxygen by the solid phase are observed. $\mathrm{Au} / \mathrm{MgO}$ is one order of magnitude more active than $\mathrm{Au} / \mathrm{SiO} \mathrm{O}_{2}$. The activation of support oxygen for the isotopic exchange reaction is related to an interaction between gold and support.
\end{abstract}

\section{INTRODUCTION}

In previous investigations, supported ruthenium and gold catalysts have been extensively characterized and tested in several hydrogen and oxygen transfer reactions $(I-9)$. From all the accumulated data, it could be concluded that the supported gold catalysts deviated markedly from known bulk properties of gold and behaved in an exceptional manner, especially when oxygen-bearing molecules were involved in the reaction. Gold, supported on magnesia, for instance, was two orders of magnitude more active in the oxygen transfer between $\mathrm{CO}$ and $\mathrm{CO}_{2}(8,10)$ than supported ruthenium and gave the same turnover number as silica-supported platinum. In an infrared study of $\mathrm{CO}$ adsorption on $\mathrm{Au} / \mathrm{MgO}$, the $\mathrm{CO}$ band maximum was shifted to a significantly lower wavenumber in comparison to the band position on $\mathrm{Au} / \mathrm{SiO}_{2}$ or $\mathrm{Au}$ films (7).

It was suggested that the observed phenomena could be related to an interaction between gold and the support. Additional

\footnotetext{
I To whom correspondence should be addressed.

${ }^{2}$ Permanent address: Istituto Donegani, Novara, Italy.

${ }^{3}$ Deceased on April 1, 1978.
}

evidence for this interaction came from an extended X-ray absorption fine structure spectroscopy (EXAFS) study which indicated the presence of a bond between gold and support oxygen $(3,5,8)$.

Information about the oxygen bond strength, the mobility of solid-phase oxygen, and presence of nonuniformities on a surface can be obtained by measuring the kinetics of the isotopic exchange of molecular oxygen $(11,14)$. In the present work, this reaction is applied to supported gold and ruthenium catalysts in order to learn more about the role of oxygen in these catalytic systems and to get more insight into the nature of the above-mentioned metal-support interaction. Theoretical and experimental aspects of the isotopic oxygen exchange reaction as a technique for the study and characterization of supported catalysts have been discussed previously (15).

In the past, the isotopic exchange reaction of molecular oxygen was mainly studied on metal oxides. Considerably less data are available for unsupported metals, such as $\mathrm{Pt}, \mathrm{Pd}, \mathrm{Ni}$, and $\mathrm{Ag}$, in the form of powders, films, or wires. The pertinent literature has been reviewed by Boreskov $(11,16)$ Novakova (17), and Ozaki $(18)$. 
In the presence of an appropriate catalyst, molecular oxygen enriched with the isotope ${ }^{18} \mathrm{O}$ can undergo two main reactions: The first reaction is a redistribution of the isotopic molecular forms with mass 32,34 , and 36, respectively, in the gas phase. The overall concentration of labeled oxygen in the gas phase remains constant. This reaction is called "homogeneous exchange":

$$
{ }^{32} \mathrm{O}_{2}+{ }^{36} \mathrm{O}_{2}=2{ }^{34} \mathrm{O}_{2}
$$

The second main reaction, called "heterogeneous exchange," involves oxygen from the solid phase. In the rate-determining step, either one or two oxygen atoms from the solid phase can participate:

$$
{ }^{36} \mathrm{O}_{2}+{ }^{16} \mathrm{O}_{\mathrm{s}}={ }^{16} \mathrm{O}^{18} \mathrm{O}+{ }^{18} \mathrm{O}_{\mathrm{s}}
$$

e.g.,

$$
{ }^{36} \mathrm{O}_{2}+2{ }^{16} \mathrm{O}_{\mathrm{s}}={ }^{32} \mathrm{O}_{2}+2{ }^{18} \mathrm{O}_{\mathrm{s}} .
$$

The homogeneous exchange reaction and the two types of heterogeneous exchange can occur simultaneously. Experimentally, the changes in the gas-phase concentrations of the molecular oxygen species with different masses are measured. The literature offers detailed mathematical treatments of the kinetic data $(11-13,19-21)$. Under favorable circumstances, it is possible to calculate the rates of the different exchange mechanisms separately.

\section{EXPERIMENTAL}

\section{Materials}

Reagent-grade $\mathrm{SiO}_{2}\left(400 \mathrm{~m}^{2} / \mathrm{g}\right.$, Carlo Erba), $\mathrm{MgO}$ (12 $\mathrm{m}^{2} / \mathrm{g}$, Carlo Erba), and $\mathrm{SiO}_{2}\left(650 \mathrm{~m}^{2} / \mathrm{g}\right.$, Davison $\left.951 \mathrm{~N}\right)$ were used as support materials. Reagent-grade precursor compounds (Rudi Pont and Carlo Erba RPE) were used throughout for catalyst preparation by impregnation or cationic exchange. The preparative procedures and the metal contents are summarized in Table 1 . The characterization included particle size determination by chemisorption, wide-angle X-ray scattering (WAXS), small-angle X-ray scattering (SAXS), and transmission electron microscopy (TEM). In the case of chemisorption, the particle size was calculated by assuming the following stoichiometries: $\mathrm{Ru} / \mathrm{H}=$ $1 / 1, \mathrm{Ru} / \mathrm{O}=1 / 2$, and $\mathrm{Au} / \mathrm{O}=2 / 1$. The details of the particle size determination have been previously reported $(5,6,8)$. A summary of the pertinent results is given in Table 2. Additional characterizations were obtained by extended X-ray absorption fine structure spectroscopy (EXAFS), X-ray photoelectron spectroscopy (XPS), diffuse reflectance spectroscopy (8), and infrared spectroscopy (7).

The equilibrium mixture of isotopic oxygen with mass 32,34 , and 36 , respectively, and with a concentration of ${ }^{18} \mathrm{O}$ equal to

\begin{tabular}{|c|c|c|c|}
\hline Support & Metal & $(w t \%)$ & Preparative method \\
\hline $\mathrm{SiO}_{2}$ (Carlo Erba) & $\mathrm{Au}$ & $2.21^{a}$ & $\begin{array}{l}\text { Cationic exchange with } \mathrm{Au}(\mathrm{en})_{2} \mathrm{Cl}_{3} \text {, } \\
\mathrm{H}_{2} \text { reduction }\left(1 \mathrm{~atm}, 400^{\circ} \mathrm{C}, 2 \mathrm{hr}\right)\end{array}$ \\
\hline MgO (Carlo Erba) & $\mathrm{Au}$ & $3.46^{b}$ & $\begin{array}{l}\text { Impregnation with } \mathrm{HAuCl}_{4}, \mathrm{H}_{2} \\
\text { reduction }\left(1 \mathrm{~atm}, 300^{\circ} \mathrm{C}, 2 \mathrm{hr} \text {; }\right. \\
\left.1 \text { atm, } 400^{\circ} \mathrm{C}, 2 \mathrm{hr}\right)\end{array}$ \\
\hline $\mathrm{SiO}_{2}$ (Davison) & $\mathrm{Ru}$ & $3.86^{b}$ & $\begin{array}{l}\text { Impregnation with } \mathrm{RuCl}_{3} \cdot \mathrm{H}_{2} \mathrm{O} \text {, } \\
\mathrm{H}_{2} \text { reduction }\left(1 \mathrm{~atm}, 300^{\circ} \mathrm{C}, 2 \mathrm{hr} ;\right. \\
\left.1 \mathrm{~atm}, 400^{\circ} \mathrm{C}, 2 \mathrm{hr}\right)\end{array}$ \\
\hline MgO (Carlo Erba) & $\mathbf{R u}$ & $4.44^{a}$ & Same as $\mathrm{Ru} / \mathrm{SiO}_{2}$ \\
\hline
\end{tabular}

TABLE 1

Composition and Preparation of Supported Gold and Ruthenium Catalysts

${ }^{a}$ By neutron activation analysis.

${ }^{b}$ By atomic absorption. 
TABLE 2

Characterization of Supported Gold and Ruthenium Catalysts

\begin{tabular}{|c|c|c|c|}
\hline \multirow[t]{2}{*}{ Catalyst } & \multicolumn{3}{|c|}{ Particle size ( $\AA$ ) } \\
\hline & Chemisorption & TEM & WAXS \\
\hline \multirow[t]{2}{*}{$\mathrm{Ru} / \mathrm{SiO}_{2}$} & $35^{a}$ & $<40$ & not detectable \\
\hline & $32^{b}$ & & \\
\hline $\mathrm{Ru} / \mathrm{MgO}$ & $129^{\circ}$ & 71 & 144 \\
\hline $\mathrm{Au} / \mathrm{SiO}_{2}$ & $61^{d}$ & 60 & 40 \\
\hline $\mathrm{Au} / \mathrm{MgO}$ & $91^{d}$ & 83 & - \\
\hline
\end{tabular}

${ }^{a} \mathrm{H}_{2}$ chemisorption at room temperature.

${ }^{b} \mathrm{O}_{2}$ chemisorption at room temperature.

${ }^{c} \mathrm{H}_{2}$ chemisorption at $100^{\circ} \mathrm{C}$.

${ }^{d} \mathrm{O}_{2}$ chemisorption at $200^{\circ} \mathrm{C}$.

$53.21 \%$ was supplied by Miles Laboratories. A nonequilibrated mixture was obtained by diluting the original equilibrium gas with ultrahigh-purity normal oxygen in a ratio of approximately $1: 1$. The ${ }^{18} \mathrm{O}$ content of the nonequilibrated mixture was 23.73 at $\%$. The dead volume of the reactor loop was measured by using ultrahigh-purity helium. Ultrahigh-purity hydrogen or oxygen, used for the catalyst pretreatment, were passed through cold traps filled with liquid nitrogen or dry ice/acetone, respectively.

\section{Apparatus}

The exchange reactions were carried out in an external recycle reactor made of Pyrex glass. The reactor, with a volume of about $3 \mathrm{ml}$, could be heated up to $450^{\circ} \mathrm{C}$. The temperature was controlled by a thermocouple and an on-off temperature controller (West, Model J). The temperature was kept constant within $\pm 1^{\circ} \mathrm{C}$ during an exchange run. A preheater section preceded the reactor inlet, and a cold trap, filled with dry ice/acetone, was placed downstream from the reactor outlet. The gas was circulated in the reactor loop by means of a magnetically driven piston pump. The pump contained a Teflon-coated glass piston filled with iron filings. The total dead volume of the reactor loop including the recirculation pump was about $50 \mathrm{ml}$. For sampling, a small amount of gas was enclosed in a capillary with a volume of about $0.2 \mathrm{ml}$, and expanded into a sample bottle. The sample bottle was then transferred to an isotope ratio mass spectrometer and the gas analyzed for the isotopic oxygen species ${ }^{32} \mathrm{O}_{2},{ }^{34} \mathrm{O}_{2},{ }^{36} \mathrm{O}_{2}$, and, as a leak test, ${ }^{28} \mathrm{~N}_{2}$. An error of about $\pm 1 \%$ was estimated. In a typical exchange run, the sample withdrawals from the reactor loop caused only a small, negligible pressure drop in the reactor loop. The reactor loop was connected to a Pyrex-glass vacuum system via high-vacuum stopcocks, lubricated by a silicone lubricant (Dow Corning High Vacuum Grease). A mercury diffusion pump backed up by a rotary pump evacuated the system. The gases used for pretreatment and reaction were stored in Pyrex-glass bulbs with break-off seals and high-vacuum stopcocks. For mixing of gases and pressure adjustment, a Toepler pump was used. Pressures were measured by two mercury-filled U-tube manometers, a McLeod manometer with a range of $10^{-2}$ $10^{-6}$ Torr and a Televac thermocouple gauge. The isotopic oxygen mixtures were introduced into the reactor loop after passing through a dry ice/acetone trap.

\section{Procedure}

A weighed sample of the catalyst (about $0.5 \mathrm{~g}$ ) with a mesh size betwen 30 and 100 mesh was placed in the reactor. Glass wool plugs above and below the sample prevented blow over of catalyst powder by the recirculating gas. All catalysts were pretreated in situ using the following initial standard procedure:

a. evacuation at room temperature (RT) to a pressure of $10^{-5}$ Torr ( 1 Torr $=133.3 \mathrm{~N} \mathrm{~m}^{-2}$ );

b. heating in vacuum from $\mathrm{RT}$ to $350^{\circ} \mathrm{C}$ in $2 \mathrm{hr}$;

c. evacuation at $350^{\circ} \mathrm{C}$ for $2 \mathrm{hr}$;

d. exposure to 100 Torr normal $\mathrm{O}_{2}$ at $350^{\circ} \mathrm{C}$ for $1 \mathrm{hr}$; 
e. evacuation at $350^{\circ} \mathrm{C}$ for $1 \mathrm{hr}$;

f. exposure to a second dose of 100 Torr normal $\mathrm{O}_{2}$ at $350^{\circ} \mathrm{C}$ for $1 \mathrm{hr}$;

g. evacuation at $350^{\circ} \mathrm{C}$ for $1 \mathrm{hr}$;

h. exposure to 100 Torr $\mathrm{H}_{2}$ at $350^{\circ} \mathrm{C}$ for $1 \mathrm{hr}$;

i. evacuation at $350^{\circ} \mathrm{C}$ for $2 \mathrm{hr}$.

After this initial procedure, the catalysts were treated prior to each individual run according to the type of reaction studied, namely, homogeneous or heterogeneous exchange.

For the heterogeneous exchange, an equilibrium mixture of isotopic oxygen was used and the uptake of ${ }^{18} \mathrm{O}$ by the solid phase was studied. The pretreatment prior to each exchange run consisted of 1-hr evacuation, 1-hr exposure to 100 Torr normal oxygen, and 1-hr evacuation at reaction temperature.

To study the homogeneous exchange (or heterophase equilibration) a net uptake of ${ }^{18} \mathrm{O}$ by the solid phase had to be suppressed. Therefore, the catalysts were enriched to the same ${ }^{18} \mathrm{O}$ content as the nonequilibrated isotopic oxygen mixture $\left(23.73 \%{ }^{18} \mathrm{O}\right)$. This was accomplished by exposing the catalysts at reaction temperature to several batches of nonequilibrium mixture until no further uptake of ${ }^{18} \mathrm{O}$ by the solid phase could be observed. In between different homogeneous exchange runs on the same sample, no further treatment was required than simply a removal of the gas phase from the previous run.

After this pretreatment procedure, the reactor loop was connected for $1 \mathrm{~min}$ to the gas inlet lines, filled with either equilibrium or nonequilibrium oxygen mixture, to allow for a pressure equilibration. Then, the reactor loop was closed and the recirculation pump started. This marked the starting point for the exchange reaction.

As a test for the reactivity of the reactor loop, a nonequilibrium isotopic oxygen mixture was circulated for $30 \mathrm{hr}$ at a reactor temperature of $450^{\circ} \mathrm{C}$. No detectable change in the gas-phase composition oc- curred. This agrees with Shakhashiri and Gordon's findings that Vycor glass is inactive for oxygen exchange up to $700^{\circ} \mathrm{C}(22)$.

Mass transfer limitations in the gas phase were tested at different pump recycle rates. A recycle rate of $0.5 \mathrm{liter} / \mathrm{min}$ was sufficient to guarantee a complete mixing of the gas phase in less than 1 min. This was proven by filling one part of the reactor loop with oxygen and the other part with nitrogen. After opening the stopcocks between the two segments, the recycle pump was started. Samples withdrawn from the loop after $1 \mathrm{~min}$ showed the same gas-phase composition as samples withdrawn after 20 min.

Mass transfer limitations within the catalyst pellets were tested by using various pellet sizes. The exchange rate remained constant for mesh sizes between 30 and 200 mesh.

\section{RESULTS AND DISCUSSION}

The rate of reaction (1) has been calculated by using the following equation:

$$
R=\frac{N_{\mathrm{g}}}{A_{\mathrm{s}}} \frac{1}{t} \ln \left[\frac{\mathrm{C}_{34}^{*}-\mathrm{C}_{34}^{0}}{\mathrm{C}_{34}^{*}-\mathrm{C}_{34}}\right] .
$$

$R$ is expressed in molecules per $A_{s} \cdot$ second, $N_{\mathrm{g}}$ represents the number of oxygen molecules in the gas phase, $A_{\mathrm{s}}$ represents the number of metal atoms on the surface of the catalyst, and $t$ is the time. $\mathrm{C}_{34}{ }^{0}, \mathrm{C}_{34}$, and $\mathrm{C}_{34}^{*}$ denote the fraction of oxygen molecules with mass 34 in the gas phase at the beginning of the reaction, at time $t$, and at the final equilibrium, respectively. The derivation of Eq. (4) is based on the following assumptions: (a) the kinetic isotope effect is negligible, (b) mass transfer limitations in the gas phase are absent, (c) the reaction system is closed and the amounts of gas withdrawn for sampling are considered negligible, and (d) the exchange reaction is the rate-determining step; the reaction mixture is in adsorption-desorption equilibrium with the catalyst.

Equation (4) is valid only when $\alpha$, the concentration of ${ }^{18} \mathrm{O}$ in the gas phase, does 
not change with time. This condition is fulfilled when solid-phase oxygen does not participate in the exchange rcaction. However, when oxygen from the solid is involved in the reaction, the condition $d \alpha / d t$ $=0$ can be maintained by enriching the catalyst with ${ }^{18} \mathrm{O}$ up to a value equal to that of the gas phase. This type of homogeneous exchange has been called "heterophase equilibration"' (17).

For the heterogeneous exchange, no attempt was made to calculate separately the rates of reactions (2) and (3). The overall rate, $R^{\prime}$, was determined, according to the mathematical treatment described by $\mathrm{Mu}$ zykantov and Panov (13), by using the following equation:

$$
R^{\prime}=-\frac{N_{\mathrm{g}}}{A_{\mathrm{s}}} \frac{1}{\alpha^{0}-\alpha_{\mathrm{s}}^{0}}\left(\frac{d \alpha}{d t}\right)^{0}\left(\frac{\text { molecules }}{A_{\mathrm{s}} \cdot \sec }\right),
$$

where $\alpha$ and $\alpha_{s}$ represent the fraction of ${ }^{18} \mathrm{O}$ in the gas phase and on the surface, respectively. The index ${ }^{0}$ refers to the values at time $t=0 .(d \alpha / d t)^{0}$ can be determined by graphical differentiation of the experimentally found time dependence of $\alpha$. Higher accuracy can be achieved by calculating $(d \alpha / d t)^{0}$ using the expression:

$$
\left(\frac{d \alpha}{d t}\right)^{0}=\left(\alpha^{0}-\gamma\right)\left(\frac{\mathrm{d} \ln \mathrm{H}}{d t}\right)^{0},
$$

where

$$
H=\frac{\alpha(t)-\gamma}{\alpha^{0}-\gamma}
$$

When the solid-phase oxygen is equivalently exchangeable, the function of $\alpha$ versus time obeys an exponential law, and $\gamma$ is the final equilibrium concentration of ${ }^{18} \mathrm{O}$ in the gas phase. For nonequivalently exchangeable oxygen, $\gamma$ represents a linearizing parameter which allows to fit the initial part of the kinetic curve ( $\alpha$ versus time) to an exponential function. In this approximation, the nonuniform surface is considered equal to a surface with a certain uniformity. The obtained rate is an average of the rates at the various parts of the nonuniform surface (13). The limitations of this approximation were discussed previously $(21)$.

The rates of the heterogeneous exchange on ruthenium, supported on $\mathrm{SiO}_{2}$ and on $\mathrm{MgO}$, were measured in the temperature range of $200-350^{\circ} \mathrm{C}$ at a total oxygen pressure of 16 Torr $\left(1\right.$ Torr $\left.=133.3 \mathrm{~N} \mathrm{~m}^{-2}\right)$. In all cases the ${ }^{18} \mathrm{O}$ content in the gas phase, $\alpha$, and the concentrations of molecular oxygen with mass 34 and mass 36 decreased with time, while the concentration of oxygen with mass 32 increased. At time $t=0$, the molecular forms of isotopic oxygen in the gas phase were in equilibrium:

$$
K=\frac{\left[{ }^{34} \mathrm{O}_{2}\right]^{2}}{\left[{ }^{32} \mathrm{O}_{2}\right]\left[{ }^{34} \mathrm{O}_{2}\right]}=4 .
$$

During the course of the reaction, the value of $K$ passed through a minimum and reached a final value of 4 at the end of the reaction. This time dependence of $\alpha,{ }^{34} \mathrm{O}_{2}$, and $K$ indicates that reaction (3) contributes to the total exchange reaction. It is not possible to exclude the simultaneous presence of reactions (1) and (2). If reaction (3) was completely absent, no change in the value of $K$ should be observed $(14,17)$.

Figure 1 shows a typical plot of $\ln H$ versus time. The value of $\gamma$ used for this graph is the experimentally found final equilibrium concentration of ${ }^{18} \mathrm{O}$ in the gas

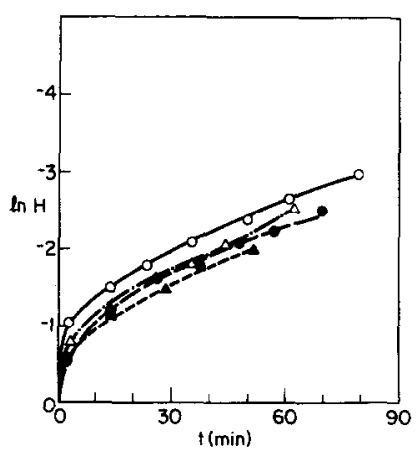

FIG. 1. In $\boldsymbol{H}$ versus time, heterogeneous exchange on $\mathrm{Ru} / \mathrm{MgO}$ and $\mathrm{Ru} / \mathrm{SiO}_{2}$, at 16 Torr oxygen pressure. O, Ru/MgO, $350^{\circ} \mathrm{C} ; \mathrm{O}, \mathrm{Ru} / \mathrm{MgO}, 300^{\circ} \mathrm{C} ; \triangle, \mathrm{Ru} / \mathrm{SiO}_{2}$, $280^{\circ} \mathrm{C} ; \Delta, \mathrm{Ru} / \mathrm{SiO}_{2}, 238^{\circ} \mathrm{C}$. 


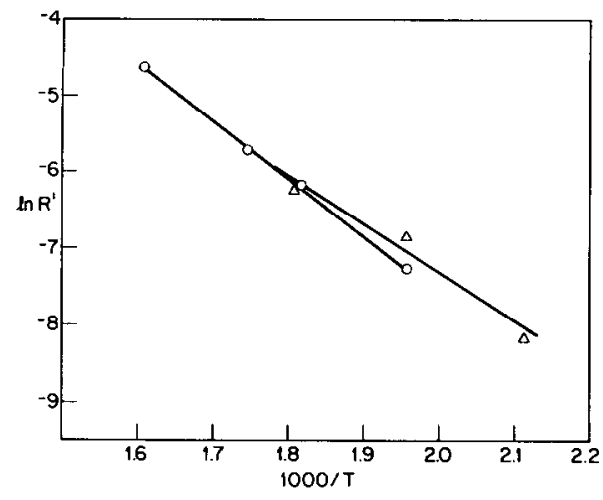

FIG. 2. Arrhenius plot for heterogeneous exchange on $\mathrm{Ru} / \mathrm{MgO}$ and $\mathrm{Ru} / \mathrm{SiO}_{2}$ at 16 Torr oxygen pressure. $\mathrm{O}, \mathrm{Ru} / \mathrm{MgO} ; \triangle, \mathrm{Ru} / \mathrm{SiO}_{2}$.

phase. The deviation from the straight line shows that the solid-phase oxygen is not equivalently exchangeable and/or that the diffusion of solid-phase oxygen is slow in comparison to the exchange.

Therefore, the above-mentioned linearizing procedure was applied in the calculation of the initial rates. Figure 2 shows the temperature dependence of these initial heterogeneous exchange rates. Activation energies of $12.6( \pm 3)$ and $14.8( \pm 3)$ $\mathrm{kcal} / \mathrm{mol}\left(1 \mathrm{kcal}=4.18 \times 10^{3} \mathrm{~J}\right)$ were determined for $\mathrm{Ru} / \mathrm{SiO}_{2}$ and $\mathrm{Ru} / \mathrm{MgO}$, respectively.

The homogeneous exchange or heterophase equilibration (reaction (1)) was studied after enriching the ruthenium catalysts with ${ }^{18} \mathrm{O}$ to a value of $23.73 \%$ equal to the gas-phase concentration of the nonequilibrated mixture. This pretreatment prevents a net uptake of ${ }^{18} \mathrm{O}$ by the solid and allows to measure the redistribution of labeled oxygen in the gas phase. The temperature dependence of reaction (1) was studied in the temperature range of 180$280^{\circ} \mathrm{C}$, at a total oxygen pressure of 16 Torr. A linear relationship between $\ln \left(\left(\mathrm{C}_{34}^{*}\right.\right.$ $\left.\left.-\mathrm{C}_{34}{ }^{0}\right) /\left(\mathrm{C}_{34}^{*}-\mathrm{C}_{34}\right)\right)$ and time was found in all cases. Therefore, Eq. (4) could be used to calculate the rate of reaction (1).

The corresponding Arrhenius plot is presented in Fig. 3. The activation energy was found to be $22.9( \pm 3) \mathrm{kcal} / \mathrm{mole}$ for
$\mathrm{Ru} / \mathrm{SiO}_{2}$ and $29.4( \pm 3) \mathrm{kcal} / \mathrm{mole}$ for $\mathrm{Ru} / \mathrm{MgO}$. The pressure dependence was measured at $240^{\circ} \mathrm{C}$ in the range of $8-40$ Torr. The order of reaction, $m$, calculated from the expression

$$
R=R_{0}\left(P_{\mathrm{O}_{2}}\right)^{m}
$$

was close to unity for both catalysts. The rate of reaction (1) was significantly higher than the heterogeneous rate. Therefore, reaction (1) can be considered as the main reaction contributing to the oxygen exchange on the ruthenium catalysts.

Previous investigations had shown difference in reactivity and selectivity toward hydrogen transfer reactions between $\mathrm{Ru} / \mathrm{MgO}$ and $\mathrm{Ru} / \mathrm{SiO}_{2}(9)$. It was suggested that particle size and/or a support effect were responsible for the observed behavior. The oxygen exchange experiments, however, did not indicate any significant difference between $\mathrm{Ru} / \mathrm{MgO}$ and $\mathrm{Ru} / \mathrm{SiO}_{2}$. The lack of sensitivity of the exchange reaction toward particle size and support effects could be related to the large oxygen affinity of ruthenium. In fact, the pretreatment used in this study is likely to lead to the formation of ruthenium oxides with the same level of oxidation, irrespective of the support. Therefore, a comparison with "reduced" ruthenium seems not justified.

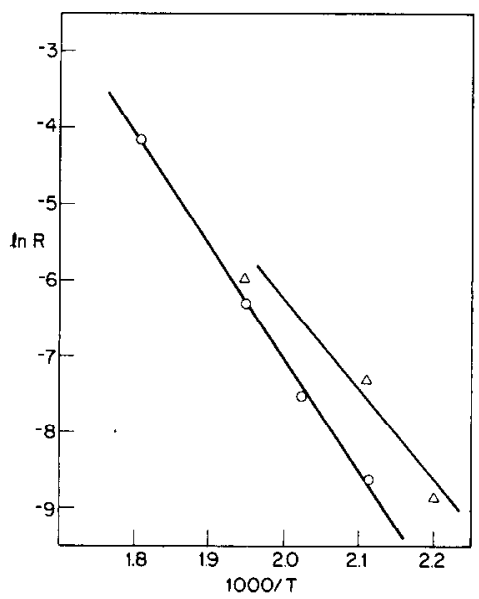

FIG. 3. Arrhenius plot for homogeneous exchange on $\mathrm{Ru} / \mathrm{MgO}$ and $\mathrm{Ru} / \mathrm{SiO}_{2}$ at 16 Torr oxygen pressure. $\mathrm{O}, \mathrm{Ru} / \mathrm{MgO} ; \triangle, \mathrm{Ru} / \mathrm{SiO}_{2}$. 
The hypothesis that the exchange reactions observed on the supported ruthenium catalysts occur actually on ruthenium oxide sites is supported by a comparison with literature data. Winter (12) found on $\mathrm{RuO}_{2}$ (BET surface area $1.06 \mathrm{~m}^{2} / \mathrm{g}$ ) that the homogeneous exchange (reaction 1) was the main reaction. He reported an activation energy of $23 \mathrm{kcal} / \mathrm{mole}$ in the temperature range of $200-280^{\circ} \mathrm{C}$ and at $300^{\circ} \mathrm{C}$ a homogeneous exchange rate of $5.5 \times 10^{14}$ molecules $\mathrm{sec}^{-1} \mathrm{~cm}^{-2}\left(\mathrm{RuO}_{2}\right)$. While the activation energies on the supported ruthenium catalysts agree very well with the value found on $\mathrm{RuO}_{2}$, the rate of reaction (1), extrapolated to $300^{\circ} \mathrm{C}$, deviates by one order of magnitude. On $\mathrm{Ru} / \mathrm{SiO}_{2}$, a rate of 4.5 $\times 10^{13}$ molecules $\mathrm{sec}^{-1} \mathrm{~cm}^{-2}(\mathrm{Ru})$ was determined, and on $\mathrm{Ru} / \mathrm{MgO}$ a rate of $4.2 \times$ $10^{13}$ molecules $\mathrm{sec}^{-1} \mathrm{~cm}^{-2}(\mathrm{Ru})$. A surface area of $9 \AA^{2}$ was assumed per ruthenium atom. The difference between Winter's rate on $\mathrm{RuO}_{2}$ and the rates on the supported ruthenium catalysts could be due to the questionable direct comparison of a $\mathrm{BET}$ surface area of $\mathrm{RuO}_{2}$ to the ruthenium metal surface area. Furthermore, Winter evacuated the normal oxygen used in the pretreatment of the $\mathrm{RuO}_{2}$ sample for only 3 min before the isotopic oxygen was admitted. This pretreatment could be insufficient to remove adsorbed oxygen completely from the surface and spurious exchange reactions with residual oxygen seem to be possible.

While unsupported gold was found to be inactive for the isotopic oxygen exchange up to a temperature of $400^{\circ} \mathrm{C}(23,24)$, the occurrence of isotopic oxygen exchange on supported gold catalysts could easily be detected. The heterogeneous exchange on $\mathrm{Au} / \mathrm{SiO}_{2}$ and $\mathrm{Au} / \mathrm{MgO}$ was studied in a temperature range of $314-370^{\circ} \mathrm{C}$ and in a pressure range of 13-63 Torr. The plot of $1 \mathrm{n}$ $H$ versus time gave on both catalysts a straight line, using in $\mathrm{Eq}$. (6) a value of $\gamma$ equal to the final equilibrium concentration of ${ }^{18} \mathrm{O}$ in the gas phase. The graph for $\mathrm{Au} / \mathrm{MgO}$ is presented in Fig. 4. This linear-

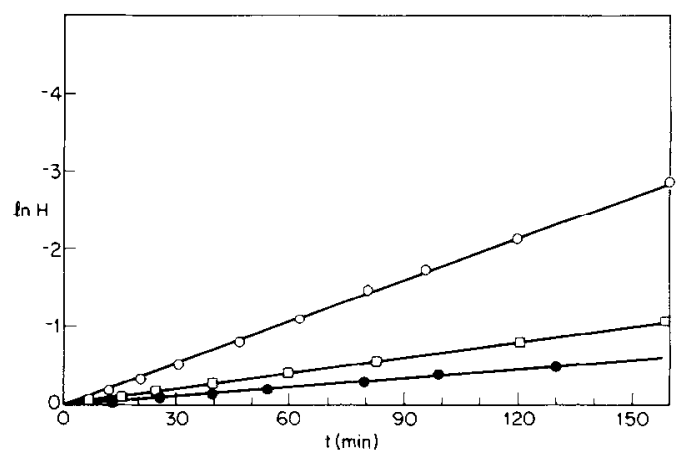

Fig. 4. In $H$ versus time, heterogeneous exchange on $\mathrm{Au} / \mathrm{MgO}$ at 16 Torr oxygen presure. $0,350^{\circ} \mathrm{C} ; \square$, $333^{\circ} \mathrm{C} ; 314^{\circ} \mathrm{C}$.

ity indicates that the solid-phase oxygen participating in the exchange is equivalent. This equivalence can be found either on a uniform surface or on a nonuniform one, provided that fast processes (as, for example diffusion) level out the label concentration at all surface centers $(13,2 l)$. Figure 5 shows the temperature dependence of the heterogeneous exchange at 16 Torr for $\mathrm{Au} / \mathrm{MgO}$ and at 22 Torr for $\mathrm{Au} / \mathrm{SiO}_{2}$. Activation energies of $36( \pm 3) \mathrm{kcal} / \mathrm{mole}$ and 40 $( \pm 3) \mathrm{kcal} / \mathrm{mole}$ were found for $\mathrm{Au} / \mathrm{MgO}$ and $\mathrm{Au} / \mathrm{SiO}_{2}$, respectively. The rates expressed per Au surface atom were more than one order of magnitude higher on $\mathrm{Au} / \mathrm{MgO}$ than on $\mathrm{Au} / \mathrm{SiO}_{2}$. Furthermore, on the $\mathrm{Au} / \mathrm{MgO}$ sample, the rate did not change with the pressure, while on $\mathrm{Au} / \mathrm{SiO}_{2}$ an order of reaction of 0.65 was determined by using expression (9).

To study the homogeneous exchange (reaction (1)), the same enrichment procedure as used for the ruthenium catalysts was attempted. However, an amount of labeled oxygen about five times higher than that needed for the ruthenium samples was insufficient to bring the ${ }^{18} \mathrm{O}$ surface composition of the gold samples to the value of $23.73 \%$, which is the ${ }^{18} \mathrm{O}$ concentration of the nonequilibrated mixture used for the homogeneous exchange reactions.

The difference in ${ }^{18} \mathrm{O}$ uptake between $\mathrm{Ru} / \mathrm{MgO}$ and $\mathrm{Au} / \mathrm{MgO}$ can be visualized by comparing the time dependence of $\alpha$ in the 


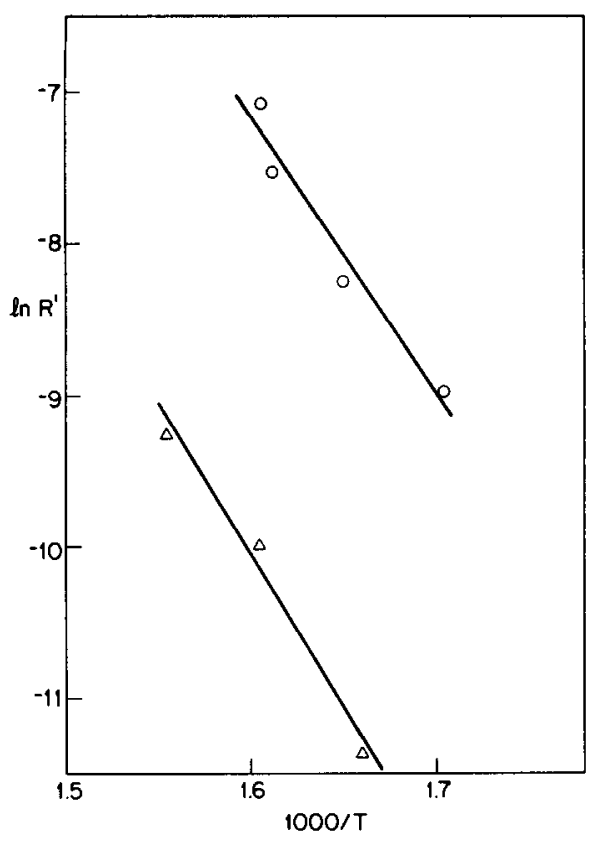

Fig. 5. Arrhenius plot for heterogeneous exchange on $\mathrm{Au} / \mathrm{MgO}$ and $\mathrm{Au} / \mathrm{SiO}_{2} . \mathrm{O}, \mathrm{Au} / \mathrm{MgO}, 16$ Torr oxygen pressure; $\triangle, \mathrm{Au} / \mathrm{SiO}_{2}, 22$ Torr oxygen pressure.

heterogeneous exchange (Fig. 6). On ruthenium, a rapid initial decrease of $\alpha$ is followed by a leveling off of the uptake. On gold, where the initial uptake is slower, a much higher amount of ${ }^{18} \mathrm{O}$ is consumed by the solid phase. The same behavior was found on the $\mathrm{SiO}_{2}$-supported samples.

The amount of exchangeable oxygen, $E$, was estimated by using the expression:

$$
E=\frac{\text { total }^{18} \mathrm{O} \text { uptake }}{W \times\left(\alpha^{*}-\alpha_{\mathrm{s}}{ }^{0}\right)},
$$

where $\alpha^{*}$ is the ${ }^{18} \mathrm{O}$ concentration in the gas phase at the final equilibrium with the solid phase, and $W$ is the weight of the catalyst in grams.

In Table 3, the values of $E$ are listed for the ruthenium and gold samples. For $\mathrm{Au} / \mathrm{SiO}_{2}$, only an estimated lower limit is reported. After $65 \mathrm{hr}$, the gas phase was still not in equilibrium with the $\mathrm{Au} / \mathrm{SiO}_{2}$ sample and further uptake of ${ }^{18} \mathrm{O}$ occurred. The experimental value of $\alpha$ at $t=65 \mathrm{hr}$ was used in Eq. (10) instead of the equilibrium value $\alpha^{*}$.
TABLE 3

Exchangeable Oxygen $E$, (Eq. (9)) on Supported Ru and $\mathrm{Au}$, at $350^{\circ} \mathrm{C}$

\begin{tabular}{lccc}
\hline Catalyst & $\begin{array}{c}A_{\mathrm{s}} \\
\text { (surface } \\
\text { metal } \\
\text { atoms/g cat) }\end{array}$ & $\begin{array}{c}\boldsymbol{A}_{\mathrm{t}} \\
\text { (total metal } \\
\text { atoms/g cat) }\end{array}$ & $\begin{array}{c}E \\
\text { (oxygen atoms/ } \\
\text { g cat) }\end{array}$ \\
\hline $\mathrm{Ru} / \mathrm{MgO}$ & $1.85 \times 10^{19}$ & $2.6 \times 10^{20}$ & $2.3 \times 10^{20}$ \\
$\mathrm{Ru} / \mathrm{SiO}_{2}$ & $6.4 \times 10^{19}$ & $2.3 \times 10^{20}$ & $1.7 \times 10^{200}$ \\
$\mathrm{Au} / \mathrm{MgO}^{20}$ & $1.3 \times 10^{19}$ & $1.1 \times 10^{20}$ & $1.5 \times 10^{21}$ \\
$\mathrm{Au} / \mathrm{SiO}_{2}$ & $1.1 \times 10^{19}$ & $6.8 \times 10^{19}$ & $>2.6 \times 10^{20}$ \\
\hline
\end{tabular}

a At $300^{\circ} \mathrm{C}$.

Let us now compare the amount of exchangeable oxygen, $E$, with the number of total metal atoms (Table 3). On ruthenium, the ratio between $E$ and the number of ruthenium metal atoms is close to unity. Therefore, from a stoichiometrical point of view, the exchangeable oxygen can be located on ruthenium, probably in the form of ruthenium oxides. However, since the ratio between $E$ and the number of ruthenium surface atoms is about 12 for $\mathrm{Ru} / \mathrm{MgO}$ and 2.5 for $\mathrm{Ru} / \mathrm{SiO}_{2}$, more than just one metal surface layer has to be involved in the exchange, at least on $\mathrm{Ru} / \mathrm{MgO}$.

On gold, on the other hand, the ratio between $E$ and the total number of gold atoms in the catalyst is about 14 for $\mathrm{Au} / \mathrm{MgO}$ and larger than 4 for $\mathrm{Au} / \mathrm{SiO}_{2}$. This rules out that oxygen linked only to gold is responsible for the exchange. Furthermore, gold oxides, such as $\mathrm{Au}_{2} \mathrm{O}$ or $\mathrm{Au}_{2} \mathrm{O}_{3}$, would be extremely unstable under

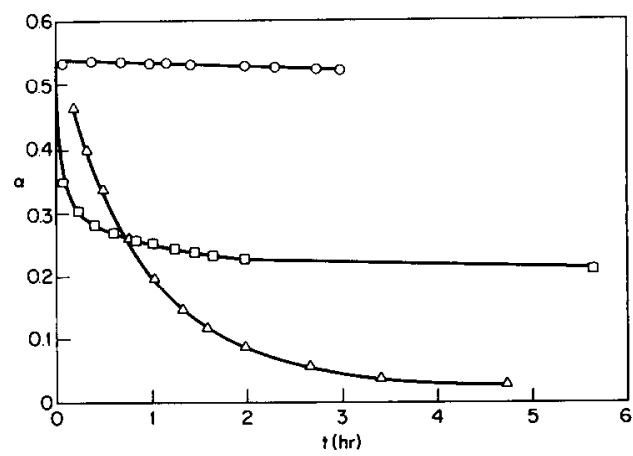

FIG. 6. Concentration of ${ }^{18} \mathrm{O}$ in the gas phase $(\alpha)$ versus reaction time. Total oxygen pressure, 16 Torr; $T=350^{\circ} \mathrm{C} . \mathrm{O}, \mathrm{MgO} ; \square, \mathrm{Ru} / \mathrm{MgO} ; \triangle, \mathrm{Au} / \mathrm{MgO}$. 
the experimental conditions $(25,26)$. Therefore, it must be concluded that support oxygen participated in the exchange reaction. Additional proof that labeled oxygen was incorporated into the solid phase of the supported gold catalysts was obtained by performing "back-exchange" experiments. After exposing the gold catalysts to the isotopic equilibrium mixture of oxygen at $350^{\circ} \mathrm{C}$ and observing the decrease in gasphase ${ }^{18} \mathrm{O}$ concentration, the reactor was evacuated overnight $\left(P<10^{-6}\right.$ Torr) at a temperature of $350^{\circ} \mathrm{C}$. Then, normal oxygen with the natural abundance of ${ }^{18} \mathrm{O}$ $(0.2 \%)$ was admitted. The gas-phase concentration of ${ }^{18} \mathrm{O}$ increased with time and the labeled oxygen consumed in the uptake reaction could be recovered.

The support materials alone were practically inactive for the isotopic oxygen exchange reaction under the experimental conditions used in the present study. On $\mathrm{SiO}_{2}$, no uptake of ${ }^{18} \mathrm{O}$ was detected over a period of $90 \mathrm{hr}$ at $350^{\circ} \mathrm{C}$. This agrees with literature data, where $\mathrm{SiO}_{2}$ was found to be inactive for the exchange reaction up to $600^{\circ} \mathrm{C}(12) . \mathrm{MgO}$ showed no uptake of ${ }^{18} \mathrm{O}$ over a period of $21 \mathrm{hr}$ at $280^{\circ} \mathrm{C}$. At $350^{\circ} \mathrm{C}$, a small uptake was observed which corresponded to less than $2 \%$ of the uptake found on $\mathrm{Au} / \mathrm{MgO}$ under the same experimental conditions.

The EXAFS data on $\mathrm{Au} / \mathrm{MgO}$ showed the presence of an $\mathrm{Au}-\mathrm{O}$ bond, indicating an interaction between gold and the support, even after reduction in $\mathrm{H}_{2}$ at $400^{\circ} \mathrm{C}$ $(3,8)$. A formation of Au-O-Mg structures resulting in a weaker bond between magnesium and oxygen could be responsible for the higher mobility of oxygen in the $\mathrm{Au} / \mathrm{MgO}$ system. However, this straightforward interpretation seems not to hold for $\mathrm{Au} / \mathrm{SiO}_{2}$. There, the EXAFS experiments did not give any evidence of a corresponding $\mathrm{Au}-\mathrm{O}-\mathrm{Si}$ structure. Nevertheless, the exchange reaction demonstrated that the oxygen is mobilized even in the $\mathrm{SiO}_{2}$ by the interaction with gold. The much lower rate of oxygen exchange on $\mathrm{Au} / \mathrm{SiO}_{2}$ points toward a weaker metal-support interaction which could be below the detection limit of the EXAFS technique. Of course, it cannot be excluded that on $\mathrm{Au} / \mathrm{SiO}_{2}$ an interaction of different nature takes place.

It can be ruled out that the high exchange activity of the supported gold catalysts is caused by impurities carried along from the reagent-grade precursor salts used in the catalyst preparation. The surface of the catalysts was analyzed by X-ray photoelectron spectroscopy $(8)$. Only in the case of the ruthenium catalysts was a contamination by chlorine found. No chlorine was found by XPS in the $\mathrm{Au} / \mathrm{MgO}$ catalyst, even before reduction. Small amounts of metallic impurities in the order of magnitude of $0.1 \%$ which can be tound in reagentgrade precursor salts can certainly not account for the massive oxygen uptake by the supported gold catalysts. This becomes evident in view of the amount of exchangeable oxygen which is one order of magnitude larger than the total number of gold atoms present in the catalyst (Table 3).

\section{CONCLUSIONS}

The results of this study have demonstrated that the isotopic exchange reaction of oxygen can provide useful information not only on metal oxides and unsupported metals but also on supported metal catalysts. The kinetics of the exchange reaction on silica- and magnesia-supported ruthenium were similar to the results found on $\mathrm{RuO}_{2}(12)$. It seems probable that the active centers for the exchange reaction on the supported ruthenium catalysts correspond to those on $\mathrm{RuO}_{2}$. In view of the experimental conditions and the large oxygen affinity of ruthenium, a formation of ruthenium oxides is likely. The amount of exchangeable oxygen suggested the contribution of more than one surface layer of ruthenium or ruthenium oxide, respectively, to the heterogeneous exchange reaction. The kinetics of the heterogeneous exchange on supported ruthenium deviated from an exponential law. This deviation is a 
criterion for nonequivalently exchangeable oxygen, caused by the presence of nonuniformities on the surface and/or contribution of diffusion. No significant difference between $\mathrm{Ru} / \mathrm{MgO}$ and $\mathrm{Ru} / \mathrm{SiO}_{2}$ could be found. In the case of supported gold, however, the support seemed to play a crucial role in the oxygen exchange reaction. A massive uptake of ${ }^{18} \mathrm{O}$ by the solid phase was observed. The heterogeneous exchange reaction obeyed an exponential law, indicating that the solid-phase oxygen was equivalently exchangeable. The striking activity of the supported gold catalysts for the oxygen exchange reaction is in marked contrast to the inactivity of unsupported gold and the support materials alone and gives further evidence for the previously postulated interaction between gold and support $(1-8)$.

\section{ACKNOWLEDGMENTS}

We express our thanks to Dr. A. E. Beshareh for helpful suggestions and his contribution to the experimental setup. Mr. M. Johnson participated in the data analysis. Financial support by the National Science Foundation through Grants ENG 75-14193 and ENG 76-11255 is gratefully acknowledged. S. G. expresses his appreciation to Montedison S.p.A. for financial support.

\section{REFERENCES}

1. Cha, D. Y., and Parravano, G., J. Catal. 18, 200 (1970).

2. Parravano, G., J. Catal. 18, 320 (1970).

3. Bassi, I. W., Lytle, F. W., and Parravano, G., J. Catal. 42, 139 (1976).

4. Galvagno, S., and Parravano, G., J. Catal. 55, 178 (1978)

5. Cocco, G., Enzo, S., Fagherazzi, G., Schiffini, L., Bassi, I. W., Vlaic, G., Galvagno, S., and Parravano, G., J. Phys. Chem. 83, 2527 (1979).
6. Fukushima, T., Galvagno, G., and Parravano, G., J. Catal. 57, 177 (1979).

7. Schwank, J., Parravano, G., and Gruber, H. L. J. Catal. 61, 19 (1980).

8. Bassi, I. W., Garbassi, F., Vlaic, G., Marzi, A., Tauszik, G. R., Cocco, G., Galvagno, S., and Parravano, G., J. Catal., in press.

9. Galvagno, S., Schwank, J., and Parravano, G., J. Catal. 61, 223 (1980).

10. Galvagno, S., and Parravano, G., Ber. Bunsenges. Phys. Chem., 83, 894 (1979).

11. Boreskov, G. K., in "Advances in Catalysis and Related Subjects" (D. D. Eley, H. Pines, and P. B. Weisz, Eds.), Vol. 15, p. 285. Academic Press, New York, 1964.

12. Winter, E. R. S., J. Chem. Soc. (London), A2889 (1968).

13. Muzykantov, V. S., and Panov, G. I., Kinet. Katal. 13, 350 (1972).

14. Klisurski, D. G., and Kuncheva, M. M., Int. Chem. Eng. 17, 488 (1977).

15. Beshareh, A. E., Ph.D. Thesis, University of Michigan, 1978.

16. Boreskov, G. K., "Fundamentals of Gas-Surface Interactions" (H. Saltsburg, J. N. Smith, Jr., and M. Rogers, Eds.). Academic Press, New York/London, 1967.

17. Novakova, J., Catal. Rev. 4, 77 (1970).

18. Ozaki, A., "Isotope Studies of Heterogeneous Catalysis." Kadansha Ltd., Tokyo and Academic Press, New York, 1977.

19. Klier, K., Novakova, J., and Jiru, P., J. Catal. 3, 479 (1963).

20. Muzykantov, V. S., Kinet. Katal. 6, 952 (1965).

21. Avetisov, A. K., Gol'dshtein, N. D., Dulin, D. A., Mischenko, Y. A., and Gel'bshtein, A. I., J. Catal. 52, 1 (1978).

22. Shakhashiri, B. Z., and Gordon, G., J. Inorg. Nucl. Chem. 28, 2525 (1966).

23. Starostina, T. S., Khasin, A. V., Boreskov, G. K., and Plyasova, L. M., Dokl. Akad. Nauk SSR 190 , 394 (1970).

24. Sachtler, W. M. H., Dorgelo, G. J. H., and Holsher, A. A., Surface Sci. 5, 221 (1966).

25. Earnshaw, A., and Harrington, T. J., "The Chemistry of the Transition Elements," pp. 86-92. Oxford Univ. Press, London, 1973.

26. Samsonov, G. V., "The Oxide Handbook," p. 221. IFI/Plenum, New York, 1973. 